\title{
Does the work environment affect designers' creativity during the creative phase depending on their personality profile? ${ }^{1}$
}

\author{
Carlos García-García ${ }^{\mathrm{a}}$, Vicente Chulvi ${ }^{\mathrm{b} *}$, Marta Royo ${ }^{\mathrm{b}}$, Jaume Gual $^{\mathrm{a}}$, Francisco Felip ${ }^{\mathrm{a}}$ \\ ${ }^{a}$ Universitat Jaume I, Dep. d’Enginyeria de Sistemes Industrials i Disseny, Castellón, Spain \\ buniversitat Jaume I, Dep. d’Enginyería Mecànica i Construcció, Av. Sos Baynat s/n E-12071, Castellón, Spain \\ * corresponding author
}

\begin{abstract}
Creativity is one of the fundamental elements to be taken into consideration in the conceptual design phases of the development of new industrial products. It is widely agreed that every individual is creative by nature and that his or her creative capacity may be conditioned by different variables within the work environment. Yet, studies that analyse these variables often treat users in a generalised manner, without paying attention to their specific characteristics.

This study sets out from the hypothesis that the user's psychological profile influences the way in which the work environment affects the designer's creativity when addressing the conceptual design phase. Thus, the aim of this study will be to determine whether developing a conceptual design proposal in a "relaxing" or an "arousing" work environment will affect all designers equally or, conversely, it will have a greater effect on some of them depending on their psychological profile.

Consequently, the first stage of the study consisted in characterising each member of the control group using the NEO-FFI test. The different users were then distributed into four groups according to the results obtained. In a second phase, each designer developed conceptual proposals for a problem in each of the environments defined for the study. A neutral environment was added as a
\end{abstract}

\footnotetext{
${ }^{1}$ For citing this manuscript, please use:

García-García, C., Chulvi, V., Royo, M., Gual, J., \& Felip, F. (2019). Does the work environment affect designers' creativity during the creative phase depending on their personality profile?. Thinking Skills and Creativity, 33, 100578.

https://doi.org/10.1016/j.tsc.2019.100578
} 
control element. Subsequently, the CPSS methodology was used to evaluate the creativity of each of the proposals designed in each of the environments.

The conclusions from the study show that there is a relationship between some personality profiles and the level of creativity achieved by the designer according to the work environment in which the conceptual proposals have been developed.

Keywords: Creativity, conceptual design, work environment, arousing, relaxing, NEO-FFI, CPSS.

\section{Introduction}

The increasingly frequent and disruptive technological changes taking place today are giving rise to variations in the behaviours of individuals and, consequently, in the way in which they seek and find solutions to the problems they face. Within this new paradigm, there is an increase in trends such as "Design Thinking", which attempts to implement the methodologies of the creative process followed by a designer or design team when tackling a problem, with the aim of finding one or several solutions to it.

In this context, it is important to highlight the importance of creativity in the design process, both within the field of design itself and in all the areas in which this process can be applied in order to offer creative solutions to a particular problem.

Regardless of the specific knowledge that someone may have about design methodologies that can enhance creativity (Csikszentmihalyi, 1998), the creative nature of the individual (Amabile, 1996) should be highlighted as one of his or her innate characteristics. We are all creative by nature, to a greater or lesser extent, depending on our experiences or the training received throughout our life. This fact, which is intrinsic to each person, will therefore influence the creativity of the design proposals that he or she can develop.

The creative capacity of the individual may be conditioned by different variables, such as the work environment, the stimuli received during the creative 
process or the interaction with other individuals, among others. A number of in-depth studies have been conducted to examine the effect of each of these variables on the individual's creative capacity and, thus, on the creativity of the results achieved (Chulvi et al., 2012) when the creative process is fostered by enhancing a particular stimulus. Some noteworthy examples include several studies that explore the role of certain physical elements that interact directly with the user or designer, such as the work of McCoy and Evans (2002) on the arrangement of furniture, that of Alves et al. (2007) on the role of teamwork in carrying out a creative task with other people, or that of Ceylan et al. (2008) on the presence of computers in the creative process. In this same line, several authors have worked on the role of lighting as a means to encourage creativity, depending on the type of light or its intensity. This is the case of the work carried out by Ceylan et al. (2008) or by Knez (1995), who also takes into account the colour temperature of the light as an additional variable affecting creativity.

There are also numerous studies that analyse the role of certain elements that interact with creativity in an indirect manner. One of the variables influencing creativity that has been explored is the effect of colours in the environment (Ceylan et al., 2008; McCoy \& Evans, 2002; Stone \& English, 1998). Other studies focus their attention on the role of different decorative elements that may be present in the environment, such as plants (Ceylan et al., 2008; Shibata \& Suzuki, 2004), posters or decorative elements (Ceylan et al., 2008; Stone, 1998) and other people with whom we do not interact (Aiello et al., 1977; Alencar \& Bruno-Faria, 1997; Stokols, Clitheroe and Zmuidzinas, 2002). Another sensory variable analysed in a number of studies is sound. Depending on the positive or negative perception of sound, creativity may be enhanced or not (Alencar \& Bruno-Faria, 1997; Kasof, 1997; Mehta \& Cheema, 2012). Knasko (1992) studied the role of odours and their effect on creativity. Analyses have also been 
conducted on the role of temperature, which can offer an adequate feeling of comfort and thus enhance creativity (Alencar \& Bruno-Faria, 1997). Other studies have addressed the influence exerted by the absence of windows, understood as referring to structural lighting elements that allow the entry of natural sunlight, depending on the climatological conditions and the geographical location (Stone, 1998). In this same line, studies have also been carried out on the influence of their existence in the workplace (Ceylan et al., 2008), a distinction being made between those that, in addition to being a source of illumination, also allow the individual to view natural or artificial outdoor elements, which may condition creativity (Stone \& Irvine, 1994; McCoy \& Evans, 2002). Alencar and Bruno-Faria (1997) also studied the effect of ventilation in the workspace, whether natural, by means of windows, or artificial, via vents, extractors or some similar means. Another related object of study has been the role played by competitiveness in the creativity of the designers' proposals. In this regard, Shalley and Oldham (1997) studied the evolution of creativity depending on the presence or absence of other competitors.

In most cases, studies that reflect upon the role of the different variables or stimuli that can influence the creativity of a user, or more specifically of a designer, deal with users in a generalised manner, without paying attention to their specific characteristics.

This study sets out from the hypothesis that the user's personality profile has an influence on the way in which the work environment affects the designer's creativity when it comes to addressing the conceptual design phase.

Consequently, the aim of this study will be to determine whether developing a conceptual design proposal in a "relaxing" or an "arousing" work environment will affect all designers equally or, conversely, it will have a greater effect on some of them 
depending on their psychological profile. To this end, a control group was set up, consisting of student designers, who will be set a series of design problems and must put forward different conceptual design solutions. In the first phase, each member of the control group was characterised using the NEO FFI test, which makes it possible to assess the five main dimensions of an individual's personality. The different users were distributed into four groups, according to the scores obtained in the dimensions that assess the way they react to their environment. In a second phase, each designer developed conceptual proposals for a problem in each of the environments defined for the study. Subsequently, the creativity of each of the proposals designed in each of the environments was rated by means of the CPSS taxonomy developed by O'Quin and Besemer (1989). This makes it possible to compare the level reached according to the stimuli received.

The conclusions from the study suggest that there may be a relationship between some personality profiles and the level of creativity achieved by the designer according to the work environment in which the conceptual proposals have been developed. If this is so, knowing the designer's personality profile would mean that the conditions of the work environment can be configured in such a way as to enhance the creativity of the proposals that he or she can develop.

\section{Methods}

\subsection{Experiment design}

\subsubsection{Sample, problem and kind of room}

To conduct the experiment, a group of students in the last year of the Bachelor's Degree in Industrial Design and Product Development Engineering at the Universitat Jaume I were asked to collaborate in the study. Since they are students trained in the field of 
design and are in the last year of their training, they were considered an ideal sample for conducting the study in question. This is, the participants have acquired the necessary skills for performing adequately the design tasks, but in the other hand, they have no long professional experience that may determine the outcomes. The students are considered as experienced users, capable of producing a variety of conceptual design proposals in a limited amount of time.

The control group comprised 18 users, both male and female, between 22 and 27 years of age. The small range of users' age is intended to neutralise any variation in the development of conceptual proposals that might be attributable to variation in the user's age.

Three different problems were posed, as indicated below, for which users had to come up with conceptual design solutions that introduce new concepts to the problem. It should be noted that the description of the problems was deliberately quite open so as to make it easier to obtain a wide range of proposals. Hence, the problems were set out very briefly and with few restraints.

- Problem 1: Elements for organisers clothing in wardrobes.

- Problem 2: Containers for taking food to University.

- Problem 3: An element for organising drawing material.

Each user was asked to attend sessions on three different days and worked on a single problem on each occasion. Although the amount of time devoted to each phase of the experiment was not excessively long, it was considered more appropriate to address just one proposal per session.

All the sessions in which users dealt with each problem within the same week were grouped together, so that all the users solved the problems posed in the same 
order. Moreover, users never coincided in each of the phases of the experiment. The aim of this was to limit the chances of interaction, which could contaminate the proposals made by the different users with concepts developed by other users or simply by their having prior knowledge of the problem to be solved. In this regard, no negligence or misconduct by users that might have a negative effect on the development of the study was observed.

Different studies argue that workplaces or work environments in which warm colours are applied enhance the user's creativity with respect to neutral environments (Stone \& English, 1998; McCoy \& Evans, 2002). Similarly, other authors claim that environments consisting of cold colours enhance the user's creativity compared to neutral environments (Ceylan, et al., 2008). Although it may seem that these two hypotheses contradict each other, it should be noted that this does not have to be so because, as they refer to neutral environments, they do not compare warm and cold environments. They therefore cannot be used to claim the existence of a contradiction in the hypotheses posited.

Furthermore, different studies defend the notion that music promotes creativity (Stokols, Clitheroe \& Zmuidzinas, 2002), and it is thus relevant to include it as a variable within the study in question when configuring each of the work environments. In this sense, it is interesting to consider the study of Kuan et al. (2017), in which the authors defend the capacity of music to relax or stress the user, depending on the type of music played. This study uses certain songs, related to a type of music capable of stressing or relaxing the user, with the particularity of their being totally unknown to the general public and, consequently, to the users in the study. In doing so, they seek to prevent a particular piece of music or song from evoking a certain sensation or feeling in the user that may be conditioned by his or her personal preference or reaction. In the 
present study, the same music was used as in the above cited study in order to ensure an arousing or relaxing reaction by users.

- Arousing music: "Conquerors of the Ages (Edmond De Luca)", "The Great Gate of Kiev (Mussorgsky)" and "The Gadfly Suite Finale (Shostakovich)".

- Relaxing music: "Appalachian Spring: Ballet for Martha (Copland)", "Sunset Near the Plantation (Frederick Delius)" and "The Birds: The Dove (Respighi)".

In order to offer a neutral element that can be used for comparison purposes, the room was also used without any kind of ambient music and with no additional chromaticity in the lighting of the environment.

The room in which all the sessions of the experiment were carried out (Fig. 1), each user working one by one following a sequential schedule, measured approximately $3 \times 3$ metres. On the left-hand side of the workplace in which each user was located there was an outer window that provided a natural source of illumination. In addition, the room could be accessed by means of a door on the right-hand side, which was kept closed while each user was working on a problem.

Variations were introduced in the arrangement of the room with the aim of neutralising the variable arrangement. In this regard, the concept of each room was made up of two elements:

- The colour of the ambient lighting, which varied between red, blue or neutral.

- The type of music played, which varied between arousing, relaxing or no music.

The colour of the ambient lighting inside the test room was determined by four LED Smart Bulb RGB bulbs with colour regulation, which allowed a large number of colours in the RGB space to be produced thanks to the combination of different intensities in each of the red, green or blue LEDs that make up the system of each bulb. 
Each of the colours of the bulbs was configured using an Android app called "BeeWi SmartPad", which is intended for the administration of home automation systems.

In addition, a plain colour image (red or blue, as appropriate) was projected onto the screen of the computer used to play the music. This screen was situated on the lefthand side of the workplace, under the window. In the case of the neutral environment, the screen was switched off while the session was being carried out.

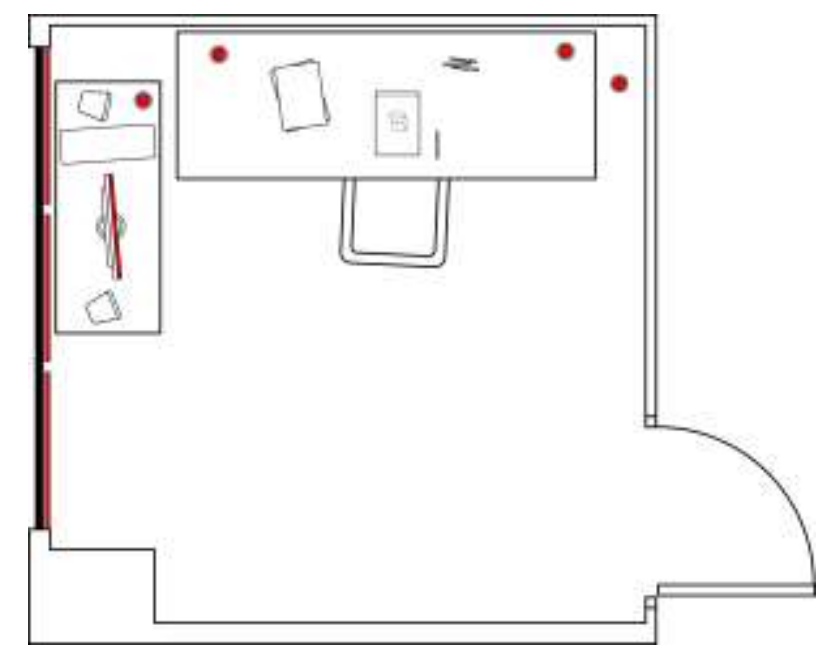

Figure 1. Plane of the test room.

The natural light coming from the side window was used to further enhance the colour of the lighting in the room by covering each of the windows with coloured cardboard (red or blue, as appropriate). By so doing the light that passed through was filtered and took on the colour of the card. In the case of the neutral room, the natural light that comes in through the window was used.

Consequently, as a result of the combination of these elements, the different rooms in which the study was conducted were as follows:

- Room 1 (Arousing): Red lighting, arousing music.

- Room 2 (Relaxing): Blue lighting, relaxing music.

- Room 3 (Neutral): White or neutral lighting, no music. 


\subsubsection{Drawing material}

Basic drawing material was used to carry out each of the case studies. Specifically, users were provided with an unlimited number of sheets of DIN-A4 paper, hard wax crayons, marker pens, pencils, a pencil sharpener and a rubber. It should be noted that the material used was the same in all cases, and the graphic quality of the proposals was not taken into account in the study.

\subsubsection{Furniture}

As regards the furniture used, the test room was equipped with a neutral office desk measuring approximately $200 \times 70 \mathrm{~cm}$, and a static office chair. The computer used to reproduce the music and project a solid colour depending on the ambience to be achieved was placed on a low piece of furniture with a neutral appearance located on the left-hand side of the workplace. To play the music, two loudspeakers were placed on the auxiliary cabinet and connected to the computer.

The user sat facing the wall throughout the experiment.

\subsection{Methodology}

In carrying out the experiment, different methodologies were used to develop the cases posed to users, to evaluate their creativity and to study some of the users' personality traits.

\subsubsection{Solving of the problems by users}

For each of the study cases, the different users were summoned to the test room individually. In the briefing room, before going into the test room, a researcher had an informal chat with each of the users in order to relax their mood a little and to try to homogenise it so that they all went into the experiment under the same conditions. 
The user entered the room, sat on the office chair and got ready to work facing the desk. The researcher then handed him or her a sheet of paper with the statement of the problem and gave the user 5 minutes to read it carefully. They were also told that they were free to ask the researcher about any doubts they might have whenever they wanted.

Once any doubts had been settled, the researcher left the room and closed the door, leaving the user alone in the test room, although they were told that they could ask for help or withdraw from the experiment if they wished to do so. The user had 20 minutes to develop as many alternative conceptual solutions to the problem as possible. Once the time was up, the user had to choose the alternative design he or she thought was the best.

They then had a further 10 minutes to transfer the proposal to the final format, which consisted of a document in DIN-A4 format with a description of the problem in the header and a surrounding frame. Once the time had elapsed, the proposal was collected and the user had to answer a short questionnaire.

On the last day of the experiment, a NEO-FFI personality test was administered to each user after completing the case and the perception questionnaire.

\subsubsection{Perception questionnaire}

On finishing each case, the user had to answer a short questionnaire (Fig. 2), in which he or she was asked about the sensations experienced while developing the conceptual proposals in that particular room. The questionnaire was repeated for each of the different room configurations, so that an assessment could be made of the user's perception when working in each of them. This would allow the researchers to identify whether there is any kind of relationship between the configuration of the room and the feeling of stress or relaxation while working in it. 


\begin{tabular}{|c|c|c|c|c|c|}
\hline & \multicolumn{5}{|c|}{ Rate your answer } \\
\hline & $\begin{array}{c}\text { Annoyed } \\
8\end{array}$ & Unconfortable & Indifferent & Confortable & Very confortable \\
\hline \multicolumn{6}{|l|}{ How have you felt in the red ambient? } \\
\hline How have you felt in the blue ambient? & & & & & \\
\hline How have you felt in the neutral amblent & & & & & \\
\hline
\end{tabular}

\begin{tabular}{lll|}
\hline What ambient did you feel most comfortable? & RED LIGHT & BLUE LGHT $\square$ \\
\hline What ambient has helped you find better ideas? & RED LIGHT & BLUE LGHT \\
\hline
\end{tabular}

Figure 2. Short questionnaire to assess the user perception in each work room.

On finishing all the cases, on the last day of the experiment, each user answered a printed NEO-FFI personality test. The user was allowed as much time as he or she deemed necessary to complete the test, the usual amount being no more than 15 or 20 minutes.

Once completed, a quick assessment of the results obtained was performed in the presence of the user, who was even asked to collaborate in determining the score obtained in each of the five dimensions studied. This evaluation was carried out taking the "Total $\mathrm{M}+\mathrm{F}$ " value as the population against which the values obtained in the test were to be compared.

Lastly, the user was given a sheet of paper with a basic interpretation of the results obtained in the test, so that he or she could leave with a simple and easily understandable summary of the results of the test, which describe his or her basic personality traits. Although the users received the evaluation of the five main dimensions of personality, only two of them were considered for the study: neuroticism and openness. The reason for choosing these two is that they are the two factors, out of the five evaluated, that indicate how changes in the work environment will affect the user. 
The combination of the scores obtained for these two factors allows the users from the study to be classified in four quadrants (Fig. 3), according to whether they are:

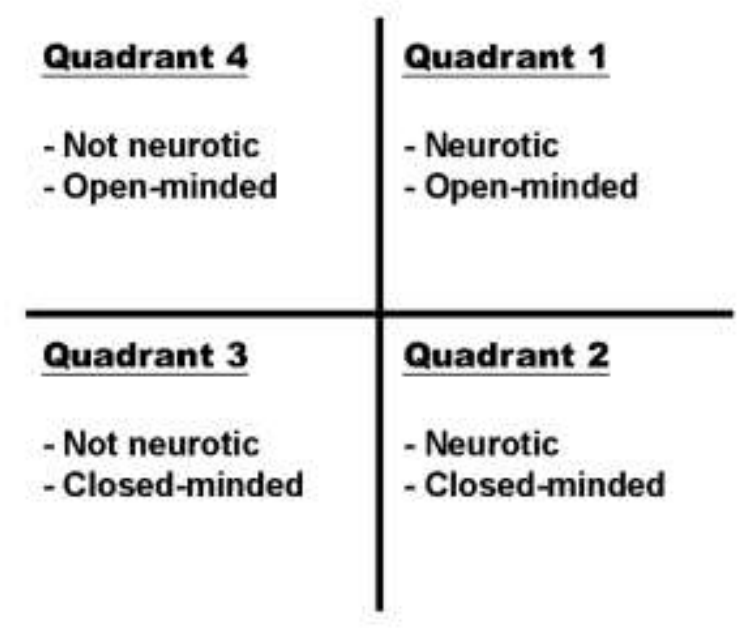

Figure 3. Representation of quadrants according to the score of the NEO-FFI dimensions Neuroticism and Openness.

In order to situate the cut-off point allowing each factor to be placed in one quadrant or another, scores in the range of the percentile 0 to 50 were taken as negative or low values (Not neurotic or Closed to change) and the scores in the range of the percentile 51 to 100 were deemed positive or high values (Neurotic or Open to change).

\subsubsection{CPSS method for evaluating solutions}

A questionnaire based on O'Quin and Besemer's (1989) CPSS taxonomy was used to rate creativity. This taxonomy allows the creativity of the conceptual proposals to be rated on the basis of three dimensions or principal parameters: the degree of novelty of the product (novelty), the coherence of the solution (resolution) and the design (style).

The parameters of Novelty and Usefullness have been considered to value Creativity, given that they are the parameters commonly used in different studies to define and value the creativity of the product. In this sense, Chulvi et al. (2012b) makes a comparative study between the parameters used by different metrics to assess 
creativity, such as CPSS (O'Quin \& Bessemer, 1989), Sarkar and Chakrabarti (2008), Moss (1966) or EPI (Justel, 2008). For the present work, this metric has been chosen mainly because, besides it has been validated several times, it can define creativity in terms of novelty and utility, and its taxonomical form allows choosing which parameters to use depending on the requirements of the study (Michael, 2000). This way, several works use adapted questionnaires according to their research needs (White \& Smith, 2001, Kurt, 2001, O’Quin \& Besemer, 2006; Chulvi, et al, 2012a).

Table 1 shows the list of semantic pairs used to rate each study case.

\begin{tabular}{|c|c|c|c|}
\hline Order no. & Adjective 1 & Adjective 2 & Inverted \\
\hline SP1 & Usual & Unusual & Yes \\
\hline SP2 & Operable & Inoperable & No \\
\hline SP3 & Startling & Stale & No \\
\hline SP4 & Non-functional & Functional & Yes \\
\hline SP5 & Surprising & Customary & No \\
\hline SP6 & Original & Conventional & No \\
\hline SP7 & Shocking & Ordinary & No \\
\hline SP8 & Unfeasible & Feasible & Yes \\
\hline SP9 & Workable & Unworkable & No \\
\hline SP10 & Novel & Predictable & No \\
\hline SP11 & Ineffective & Effective & Yes \\
\hline SP12 & Useful & Useless & No \\
\hline
\end{tabular}

Table 1. Adapted list of semantic pairs for rating creativity by means of CPSS (O'Quin \& Besemer, 1989).

The method consisted in rating each conceptual design proposal by scoring the different semantic pairs on a 7-point Likert scale (from 1 to 7). Each rater had to score 12 semantic pairs for each of the 18 alternative design solutions that users developed in each of the three work environment they were set. In order to facilitate the rating process and avoid making it too tedious, a Google form was used to score each solution, grouped according to the problem posed. In this way, each rater was able to rate each problem at a different time. 
The proposals were rated by six raters, all of whom were lecturers from the Bachelor's Degree in Industrial Design and Product Development Engineering at the Universitat Jaume I. The scores of one of them were discarded after an inter-rater agreement assessment using Pearson's correlation coefficient, since the level of agreement with the other raters was considered too low. The inter-rater agreement considering the six evaluators was $r=0.341$, which is considered low positive correlation, while the inter-rater agreement without this evaluator raise to $r=0.443$, which is considered as moderate positive correlation.

\section{Results}

As a result, of the work carried out in each of the work environments, different conceptual design proposals have been obtained, as illustrated with examples in (Fig. 4).
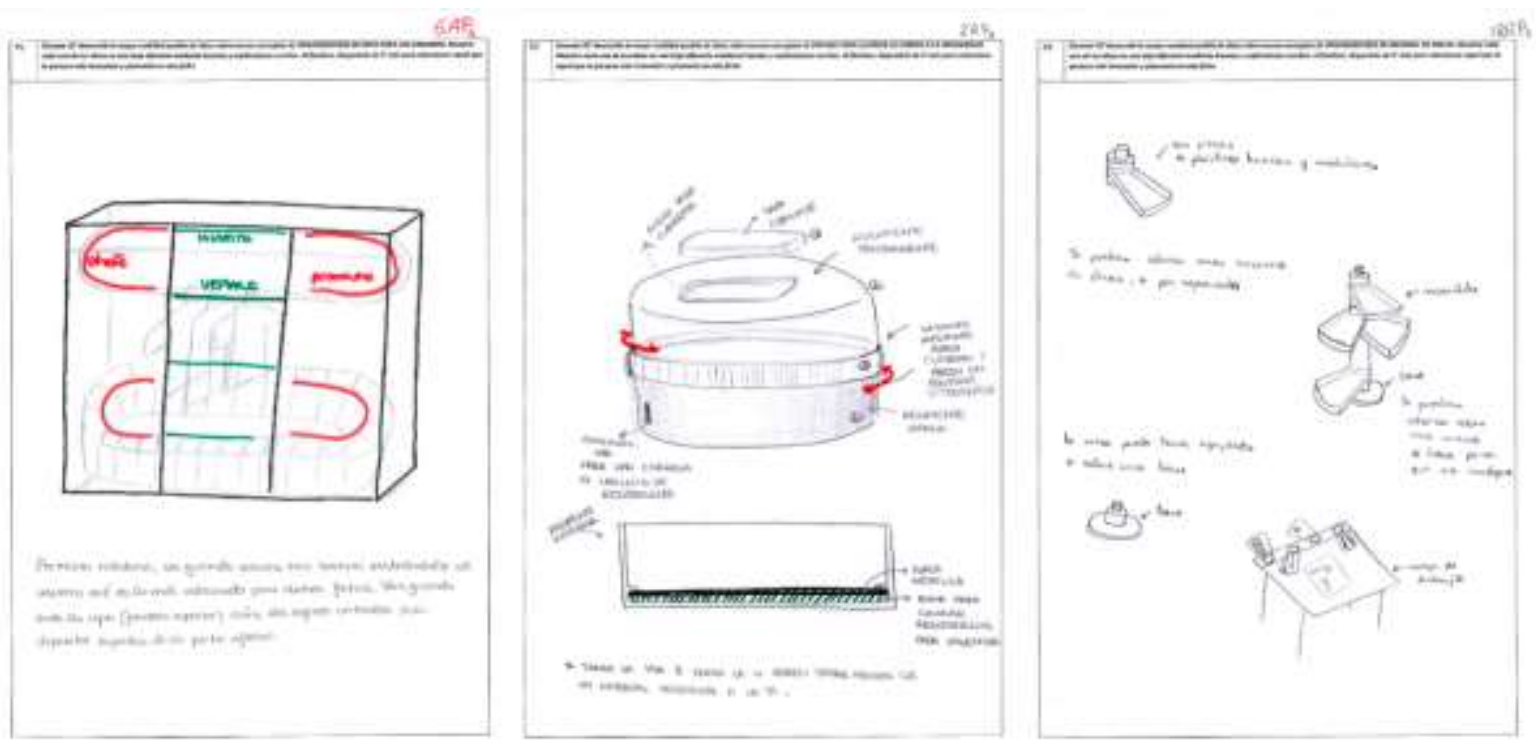

Figure 4. Conceptual design examples obtained in the experiment.

Based on the analysis of the conceptual design proposals developed throughout the experiment, and from different values collected during the case study, the results presented below have been obtained. 


\subsection{Results of the NEO-FFI personality test}

Each of the quadrants in Figure 3 was taken as representing a personality profile or Type of user. Table 2 thus shows the users who participated in the experiment classified by types, according to the results of the NEO-FFI test conducted on each user at the end of the experiment.

\begin{tabular}{|c|c|c|c|}
\hline User type & Neuroticism & Openness & Number of users \\
\hline Type 1 / Quadrant 1 & $51-100$ & $51-100$ & 8 \\
\hline Type 2 / Quadrant 2 & $51-100$ & $0-50$ & 5 \\
\hline Type 3 / Quadrant 3 & $0-50$ & $0-50$ & 1 \\
\hline Type 4 / Quadrant 4 & $0-50$ & $51-100$ & 4 \\
\hline
\end{tabular}

Table 2. Results of the NEO-FFI personality test on paper.

In Figure 5, the personality profiles obtained by means of the NEO-FFI test for the dimensions "Neuroticism" and "Openness", based on the values obtained by each of the 18 users who participated in the study, can be seen distributed in quadrants.

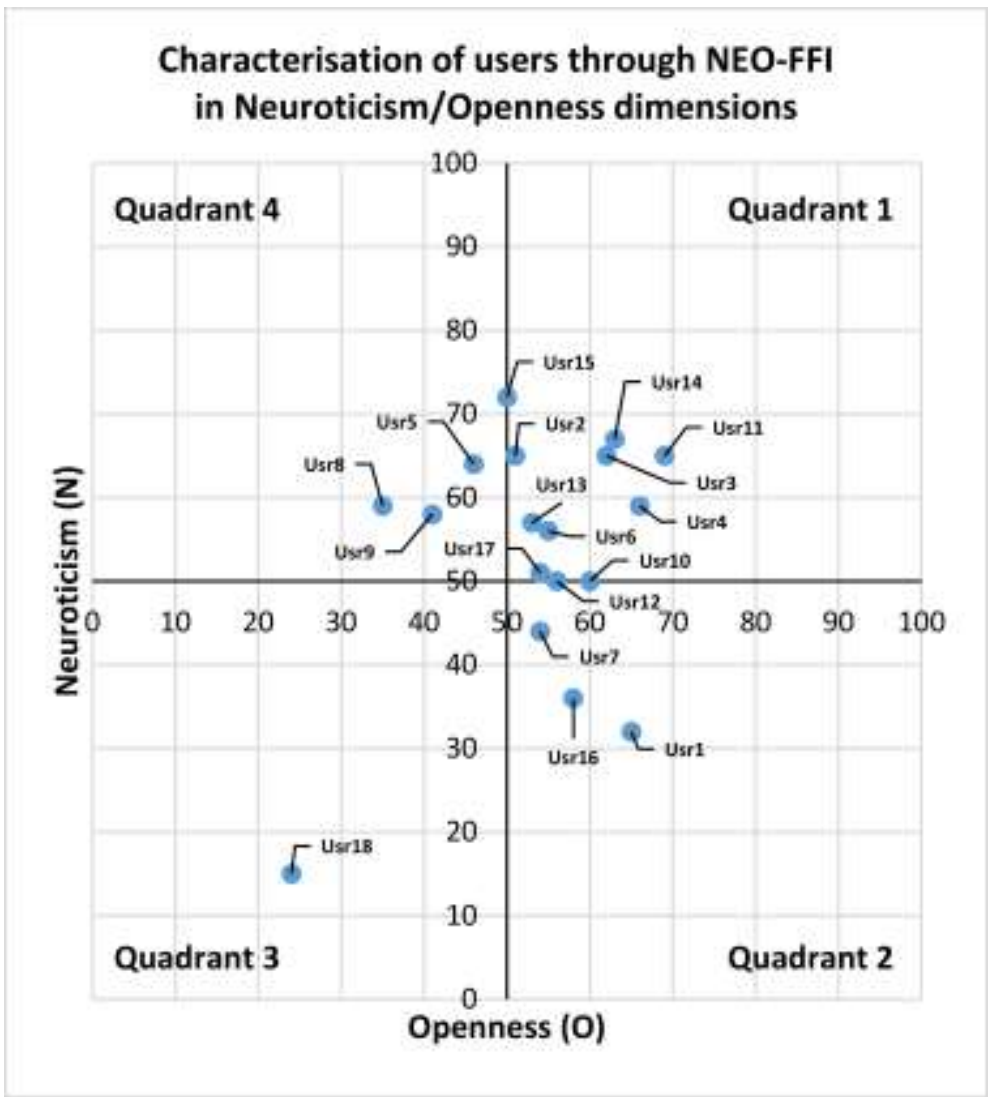


Figure 5. Characterisation of users by the NEO-FFI on the Neuroticism/ Openness dimensions.

\subsection{Results of the creativity of the conceptual design proposals (CPSS)}

The creativity of each of the conceptual design proposals was rated using the scores given by each of the five raters for the parameters Novelty, Resolution and Creativity, with an inter-rater agreement of $r=0.443$. 


\begin{tabular}{|c|c|c|c|c|c|c|c|c|c|c|c|c|c|c|c|}
\hline \multirow[b]{2}{*}{$\begin{array}{l}\dot{\bar{\Xi}} \\
\stackrel{\mathscr{D}}{\bullet}\end{array}$} & \multirow[b]{2}{*}{ 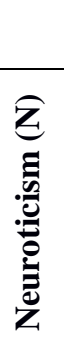 } & \multirow[b]{2}{*}{ 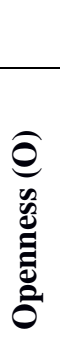 } & \multirow[b]{2}{*}{ 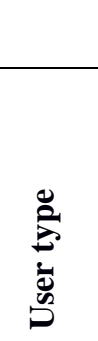 } & \multicolumn{4}{|c|}{ Arousing } & \multicolumn{4}{|c|}{ Relaxing } & \multicolumn{4}{|c|}{ Neutral } \\
\hline & & & & $\begin{array}{l}\frac{\Xi}{0} \\
\frac{0}{0} \\
0 \\
0\end{array}$ & 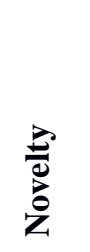 & 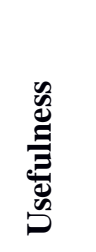 & نِّ & $\begin{array}{l}\frac{\Xi}{0} \\
\frac{0}{0} \\
0 \\
0\end{array}$ & $\begin{array}{l}\text { 름 } \\
\overline{0} \\
z \\
z\end{array}$ & 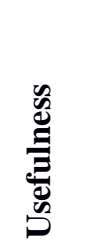 & : & $\frac{\Xi}{\frac{\pi}{0}}$ & 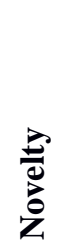 & 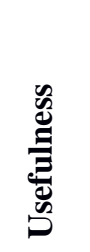 & 苞 \\
\hline Usr1 & 65 & 32 & Type 2 & P1 & 5.238 & 5.619 & 5.429 & $\mathrm{P} 2$ & 5.762 & 5.476 & 5.619 & P3 & 5.619 & 5.667 & 5.643 \\
\hline Usr2 & 51 & 65 & Type 1 & $\mathrm{P} 1$ & 5.667 & 5.762 & 5.714 & $\mathrm{P} 2$ & 5.048 & 5.524 & 5.286 & P3 & 4.333 & 5.286 & 4.810 \\
\hline Usr3 & 62 & 65 & Type 1 & P1 & 6.714 & 5.381 & 6.048 & $\mathrm{P} 2$ & 5.905 & 5.524 & 5.714 & P3 & 7.095 & 5.524 & 6.310 \\
\hline Usr4 & 66 & 59 & Type 1 & P1 & 7.190 & 5.524 & 6.357 & $\mathrm{P} 2$ & 6.048 & 5.571 & 5.810 & P3 & 6.571 & 5.667 & 6.119 \\
\hline Usr5 & 46 & 64 & Type 4 & P1 & 6.190 & 5.429 & 5.810 & $\mathrm{P} 2$ & 6.381 & 5.524 & 5.952 & P3 & 6.952 & 5.619 & 6.286 \\
\hline Usr6 & 55 & 56 & Type 1 & P1 & 4.190 & 5.762 & 4.976 & $\mathrm{P} 2$ & 4.667 & 5.762 & 5.214 & P3 & 6.238 & 5.667 & 5.952 \\
\hline Usr7 & 54 & 44 & Type 2 & P3 & 5.429 & 5.667 & 5.548 & P1 & 6.381 & 5.524 & 5.952 & $\mathrm{P} 2$ & 7.286 & 5.619 & 6.452 \\
\hline Usr8 & 35 & 59 & Type 4 & P3 & 8.095 & 5.429 & 6.762 & P1 & 5.333 & 5.571 & 5.452 & $\mathrm{P} 2$ & 4.857 & 5.762 & 5.310 \\
\hline Usr9 & 41 & 58 & Type 4 & P3 & 5.524 & 5.381 & 5.452 & $\mathrm{P} 1$ & 4.619 & 5.714 & 5.167 & $\mathrm{P} 2$ & 5.286 & 5.619 & 5.452 \\
\hline Usr10 & 60 & 50 & Type 2 & P3 & 7.381 & 5.524 & 6.452 & P1 & 5.190 & 5.667 & 5.429 & $\mathrm{P} 2$ & 6.333 & 5.857 & 6.095 \\
\hline Usr11 & 69 & 65 & Type 1 & P3 & 4.905 & 5.667 & 5.286 & P1 & 3.048 & 6.000 & 4.524 & $\mathrm{P} 2$ & 3.190 & 5.476 & 4.333 \\
\hline Usr12 & 56 & 50 & Type 2 & P3 & 5.619 & 5.286 & 5.452 & P1 & 5.143 & 5.286 & 5.214 & P2 & 5.905 & 5.667 & 5.786 \\
\hline Usr13 & 53 & 57 & Type 1 & $\mathrm{P} 2$ & 5.714 & 5.667 & 5.690 & P3 & 5.048 & 5.810 & 5.429 & P1 & 7.095 & 5.476 & 6.286 \\
\hline Usr14 & 63 & 67 & Type 1 & $\mathrm{P} 2$ & 6.286 & 5.714 & 6.000 & P3 & 6.857 & 5.476 & 6.167 & P1 & 3.762 & 5.857 & 4.810 \\
\hline Usr15 & 50 & 72 & Type 4 & P2 & 7.143 & 5.714 & 6.429 & P3 & 6.143 & 5.476 & 5.810 & P1 & 7.476 & 5.714 & 6.595 \\
\hline Usr16 & 58 & 36 & Type 2 & $\mathrm{P} 2$ & 5.524 & 5.524 & 5.524 & P3 & 6.095 & 5.571 & 5.833 & P1 & 5.000 & 5.952 & 5.476 \\
\hline Usr17 & 54 & 51 & Type 1 & $\mathrm{P} 2$ & 6.810 & 5.762 & 6.286 & P3 & 5.524 & 5.714 & 5.619 & P1 & 4.571 & 5.238 & 4.905 \\
\hline Usr18 & 24 & 15 & Type 3 & $\mathrm{P} 2$ & 6.571 & 5.667 & 6.119 & P3 & 5.667 & 5.714 & 5.690 & P1 & 4.714 & 5.619 & 5.167 \\
\hline & & & & & 6.122 & 5.582 & 5.852 & & 5.492 & 5.606 & 5.549 & & 5.683 & 5.627 & 5.655 \\
\hline
\end{tabular}

Table 3. Results of rating the Creativity of the conceptual design proposals produced by the users in each work environment by means of CPSS (O'Quin \& Besemer, 1989).

Table 3 shows the results of the rating (out of 10) of the creativity of the conceptual design proposals produced by the users in each type of environment, by means of the CPSS metric (O'Quin \& Besemer, 1989). The type of user that obtained each of the novelty and usefulness, and therefore creativity, ratings was also highlighted, together with the problem that each of them worked on in each of the environments.

The different ANOVAS presented in Table 4 were calculated to compare the significance of the results obtained in the CPSS ratings for the parameters of novelty, 
usefulness and creativity, according to user type, the environment or the interaction of the two.

\begin{tabular}{|c|c|c|c|}
\cline { 2 - 4 } \multicolumn{1}{c|}{} & Novelty & Usefullness & Creativity \\
\hline By user type & $\mathrm{F}(3,42)=.972, \mathrm{p}=.415$ & $\mathrm{~F}(3,42)=.340, \mathrm{p}=.797$ & $\mathrm{~F}(3,42)=.900, \mathrm{p}=.449$ \\
\hline By environment & $\mathrm{F}(2,42)=1.387, \mathrm{p}=.261$ & $\mathrm{~F}(2,42)=.376, \mathrm{p}=.689$ & $\mathrm{~F}(2,42)=1.282, \mathrm{p}=.288$ \\
\hline $\begin{array}{c}\text { By interaction } \\
\text { (Type.Environment) }\end{array}$ & $\mathrm{F}(6,42)=.386, \mathrm{p}=.884$ & $\mathrm{~F}(6,42)=2.434, \mathrm{p}=. \mathbf{0 4 1}$ & $\mathrm{F}(6,42)=.566, \mathrm{p}=.755$ \\
\hline
\end{tabular}

Table 4. ANOVAS for rating the significance $(\alpha=0.05)$ of the creativity results obtained by CPSS, depending on the type of user (all Type), the environment or the interaction of the two.

As the number of Type 3 students is considered as a small sample, the statistical analysis has been performed again taking out this sample, in order to check if it has influence in the results. Results are shown in Table 5. There, it can be seen that the conclusions in terms of significance are the same.

\begin{tabular}{|c|c|c|c|}
\cline { 2 - 4 } \multicolumn{1}{c|}{} & Novelty & Usefullness & Creativity \\
\hline By user type & $\mathrm{F}(2,42)=1.441, \mathrm{p}=.248$ & $\mathrm{~F}(2,42)=.261, \mathrm{p}=.772$ & $\mathrm{~F}(2,42)=1.346, \mathrm{p}=.271$ \\
\hline By environment & $\mathrm{F}(2,42)=1.301, \mathrm{p}=.283$ & $\mathrm{~F}(2,42)=1.574, \mathrm{p}=.219$ & $\mathrm{~F}(2,42)=1.284, \mathrm{p}=.288$ \\
\hline $\begin{array}{c}\text { By interaction } \\
\text { (Type.Environment) }\end{array}$ & $\mathrm{F}(4,42)=.334, \mathrm{p}=.853$ & $\mathrm{~F}(4,42)=3.568, \mathrm{p}=. \mathbf{0 1 4}$ & $\mathrm{F}(4,42)=.549, \mathrm{p}=.701$ \\
\hline
\end{tabular}

Table 5. ANOVAS for rating the significance $(\alpha=0.05)$ of the creativity results obtained by CPSS, depending on the type of user (T1, T2 and T4), the environment or the interaction of the two.

\subsection{Perception questionnaire}

Table 6 shows the results collected from the questionnaires answered by the designers at the end of each of the cases posed. The values specified for how the users felt in each environment are presented, together with the problem they worked on in that environment. The scores indicated by the users in the questionnaires answered at the end of each of the cases regarding how they felt while working in each of the 
environments were expressed on a 5-point Likert scale graduated by descriptors (Fig.

2). 


\begin{tabular}{|c|c|c|c|c|c|c|c|c|c|c|c|c|c|}
\hline \multirow{3}{*}{ 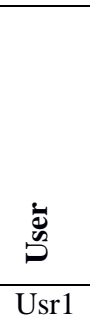 } & \multicolumn{2}{|c|}{ Neuroticism $(\mathbf{N})$} & \multicolumn{2}{|c|}{ Openness (O) } & \multirow[b]{2}{*}{ 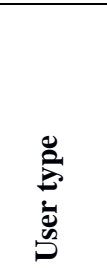 } & \multicolumn{8}{|c|}{ Opinion questionnaire (Likert 1-5) } \\
\hline & 总 & :气 & 总 & $\stackrel{0}{: 0}$ & & & $\frac{\Xi}{0}$ & $\approx$ & : & & $\begin{array}{l}1 \\
\frac{10}{0} \\
0 \\
0 \\
0\end{array}$ & 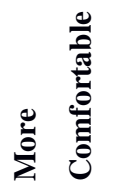 & 这 \\
\hline & 65 & very high & 32 & very low & Type 2 & 2 & $\mathrm{P} 1$ & 4 & P2 & 3 & P3 & relaxing & relaxing \\
\hline Usr2 & 51 & middle & 65 & very high & Type 1 & 2 & $\mathrm{P} 1$ & 4 & P2 & 5 & P3 & neutral & neutral \\
\hline Usr3 & 62 & high & 65 & very high & Type 1 & 3 & P1 & 4 & $\mathrm{P} 2$ & 5 & $\mathrm{P} 3$ & neutral & neutral \\
\hline Usr4 & 66 & very high & 59 & high & Type 1 & 3 & P1 & 5 & P2 & 4 & P3 & relaxing & relaxing \\
\hline Usr5 & 46 & middle & 64 & high & Type 4 & 2 & $\mathrm{P} 1$ & 3 & P2 & 5 & P3 & relaxing & relaxing \\
\hline Usr6 & 55 & high & 56 & high & Type 1 & 2 & P1 & 5 & P2 & 4 & P3 & relaxing & relaxing \\
\hline Usr7 & 54 & middle & 44 & low & Type 2 & 2 & P3 & 5 & $\mathrm{P} 1$ & 4 & $\mathrm{P} 2$ & relaxing & neutral \\
\hline Usr8 & 35 & low & 59 & high & Type 4 & 4 & P3 & 5 & P1 & 3 & P2 & relaxing & relaxing \\
\hline Usr9 & 41 & low & 58 & high & Type 4 & 1 & P3 & 3 & P1 & 3 & P2 & neutral & neutral \\
\hline Usr10 & 60 & high & 50 & middle & Type 2 & 2 & P3 & 4 & P1 & 4 & $\mathrm{P} 2$ & relaxing & relaxing \\
\hline Usr11 & 69 & very high & 65 & very high & Type 1 & 1 & P3 & 5 & P1 & 3 & $\mathrm{P} 2$ & relaxing & relaxing \\
\hline Usr12 & 56 & high & 50 & middle & Type 2 & 2 & P3 & 4 & P1 & 4 & P2 & neutral & relaxing \\
\hline Usr13 & 53 & middle & 57 & high & Type 1 & 3 & $\mathrm{P} 2$ & 5 & P3 & 2 & P1 & relaxing & relaxing \\
\hline Usr14 & 63 & high & 67 & very high & Type 1 & 4 & $\mathrm{P} 2$ & 4 & P3 & 3 & $\mathrm{P} 1$ & relaxing & neutral \\
\hline Usr15 & 50 & middle & 72 & very high & Type 4 & 4 & $\mathrm{P} 2$ & 5 & P3 & 3 & $\mathrm{P} 1$ & relaxing & relaxing \\
\hline Usr16 & 58 & high & 36 & low & Type 2 & 3 & $\mathrm{P} 2$ & 3 & P3 & 4 & P1 & neutral & arousing \\
\hline Usr17 & 54 & middle & 51 & middle & Type 1 & 1 & $\mathrm{P} 2$ & 5 & P3 & 4 & P1 & relaxing & neutral \\
\hline Usr18 & 24 & high & 15 & very low & Type 3 & 2 & $\mathrm{P} 2$ & 5 & P3 & 3 & P1 & relaxing & neutral \\
\hline
\end{tabular}

Table 6. Results of the perception questionnaire completed by the users after each of the cases they solved.

Figure 6 offers a graphical representation of the position of each user in each quadrant according to the results obtained in the NEO-FFI personality test, taking into account the Neuroticism (N) and Openness (O) dimensions; it also indicates the environment in which they felt most comfortable while working. Along these lines, Figure 7 shows the same distribution of users, indicating the work environment in which they felt most creative. 


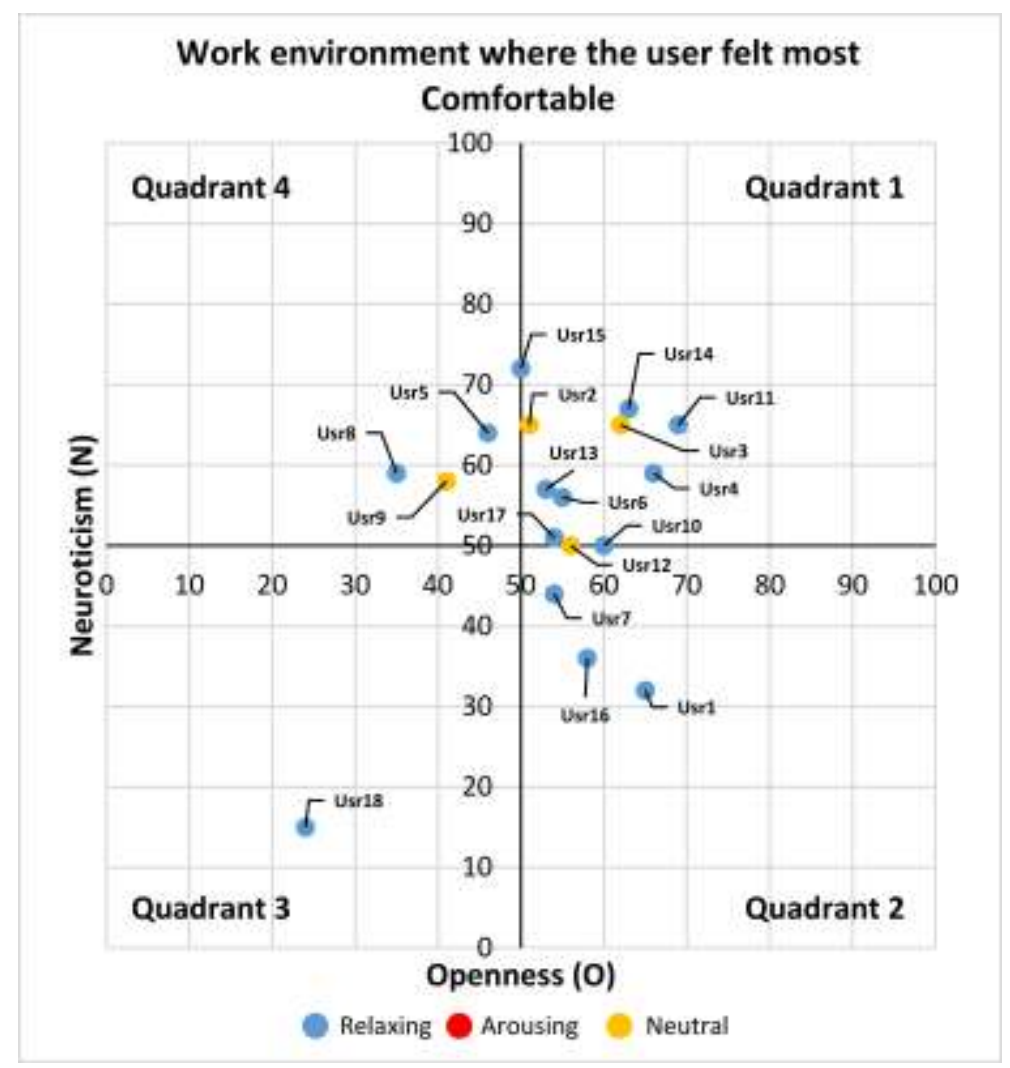

Figure 6. Work environment in which users felt more Comfortable depending on their characterisation by the NEO-FFI in the Neuroticism/ Openness dimensions.

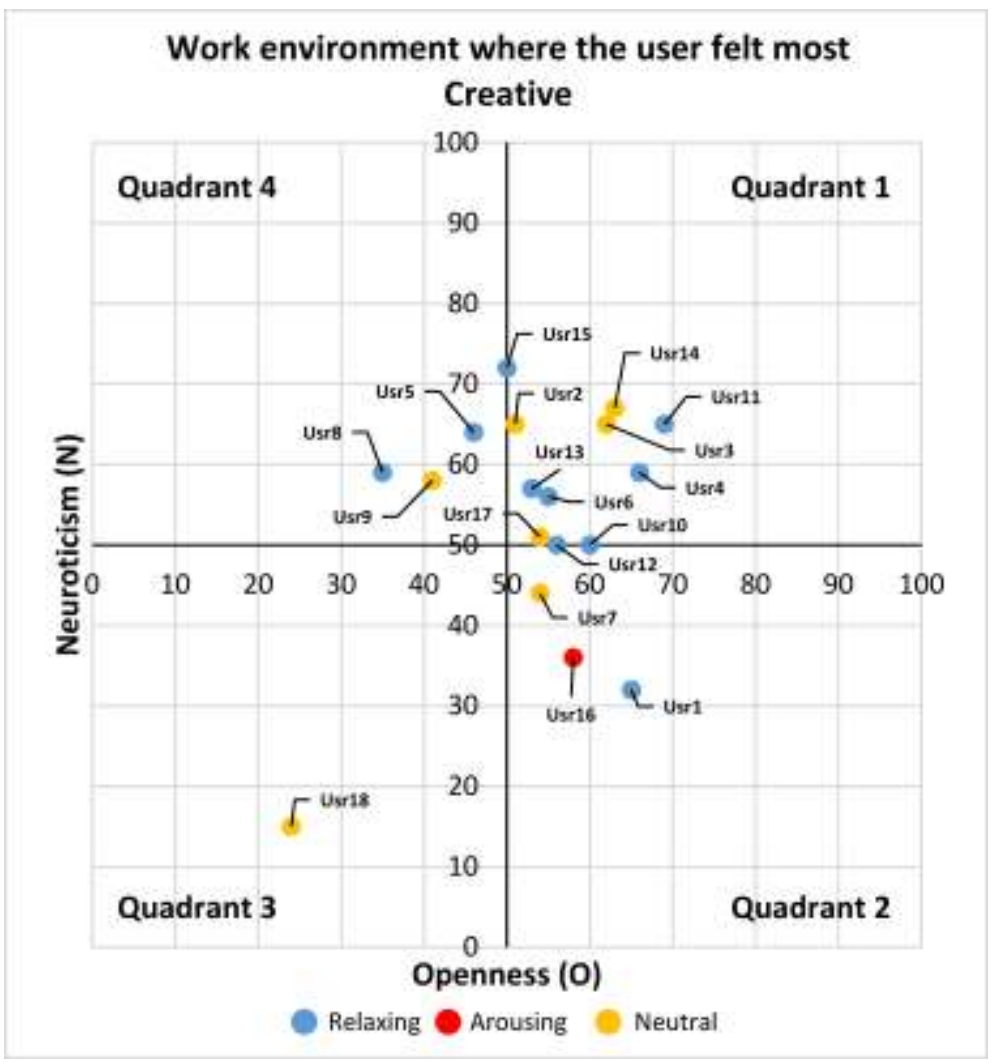


Figure 7. Work environment in which users felt more Creativity depending on their characterisation by the NEO-FFI in the Neuroticism/ Openness dimensions.

\subsection{Comparative study of the results}

In order to facilitate the analysis of the results obtained in each part of the study, different comparative figures and tables of results are presented.

Table 7 shows a comparative traceability study, for each type of user, of the environment in which he or she felt most comfortable, or most creative, together with the environment in which the measurements of creativity carried out by CPSS yielded their highest values.

\begin{tabular}{|c|c|c|c|c|}
\hline User type & User & $\begin{array}{c}\text { Felt more } \\
\text { comfortable }\end{array}$ & $\begin{array}{l}\text { Felt more } \\
\text { creative }\end{array}$ & $\begin{array}{c}\text { More creative } \\
\text { (measured by CPSS) }\end{array}$ \\
\hline \multirow[t]{8}{*}{ Type 1} & Usr2 & Neutral & Neutral & Arousing \\
\hline & Usr3 & Neutral & Neutral & Neutral \\
\hline & Usr4 & Relaxing & Relaxing & Arousing \\
\hline & Usr6 & Relaxing & Relaxing & Neutral \\
\hline & Usr11 & Relaxing & Relaxing & Relaxing \\
\hline & Usr13 & Relaxing & Relaxing & Neutral \\
\hline & Usr14 & Relaxing & Neutral & Relaxing \\
\hline & Usr17 & Relaxing & Neutral & Arousing \\
\hline \multirow[t]{5}{*}{ Type 2} & Usr1 & Relaxing & Relaxing & Neutral \\
\hline & Usr7 & Relaxing & Neutral & Neutral \\
\hline & Usr10 & Relaxing & Relaxing & Arousing \\
\hline & Usr12 & Neutral & Relaxing & Neutral \\
\hline & Usr16 & Neutral & Arousing & Relaxing \\
\hline Type 3 & Usr18 & Relaxing & Neutral & Arousing \\
\hline \multirow[t]{4}{*}{ Type 4} & Usr5 & Relaxing & Relaxing & Neutral \\
\hline & Usr8 & Relaxing & Relaxing & Arousing \\
\hline & Usr9 & Neutral & Neutral & Neutral \\
\hline & Usr15 & Relaxing & Relaxing & Neutral \\
\hline
\end{tabular}

Table 7. Comparison between the environment in which they obtained the highest rating, according to the feelings expressed by each user in the surveys after working in each type of environment, and the rating for creativity measured by the CPSS. 
A study was conducted, for each type of user, to compare the feelings while working in each type of environment, expressed by each type of user in the surveys, and the creativity rating measured by CPSS. Figure 8 shows the percentages of users who claimed that they felt more comfortable or more creative in a certain environment. Likewise, the percentage of users who were actually more creative in that type of environment is also presented. This makes it possible to study the correspondence between user perceptions and the results obtained from measurements.

The Creativity applied in the conceptual design proposals produced by each user in each type of environment was studied by examining the distribution of ratings according to the type of room. Figure 9 shows the distribution of those ratings for the parameters of novelty and usefulness, and creativity as the product of the two. Along these lines, Figure 10 shows the distributions for these same parameters, but by type of user.

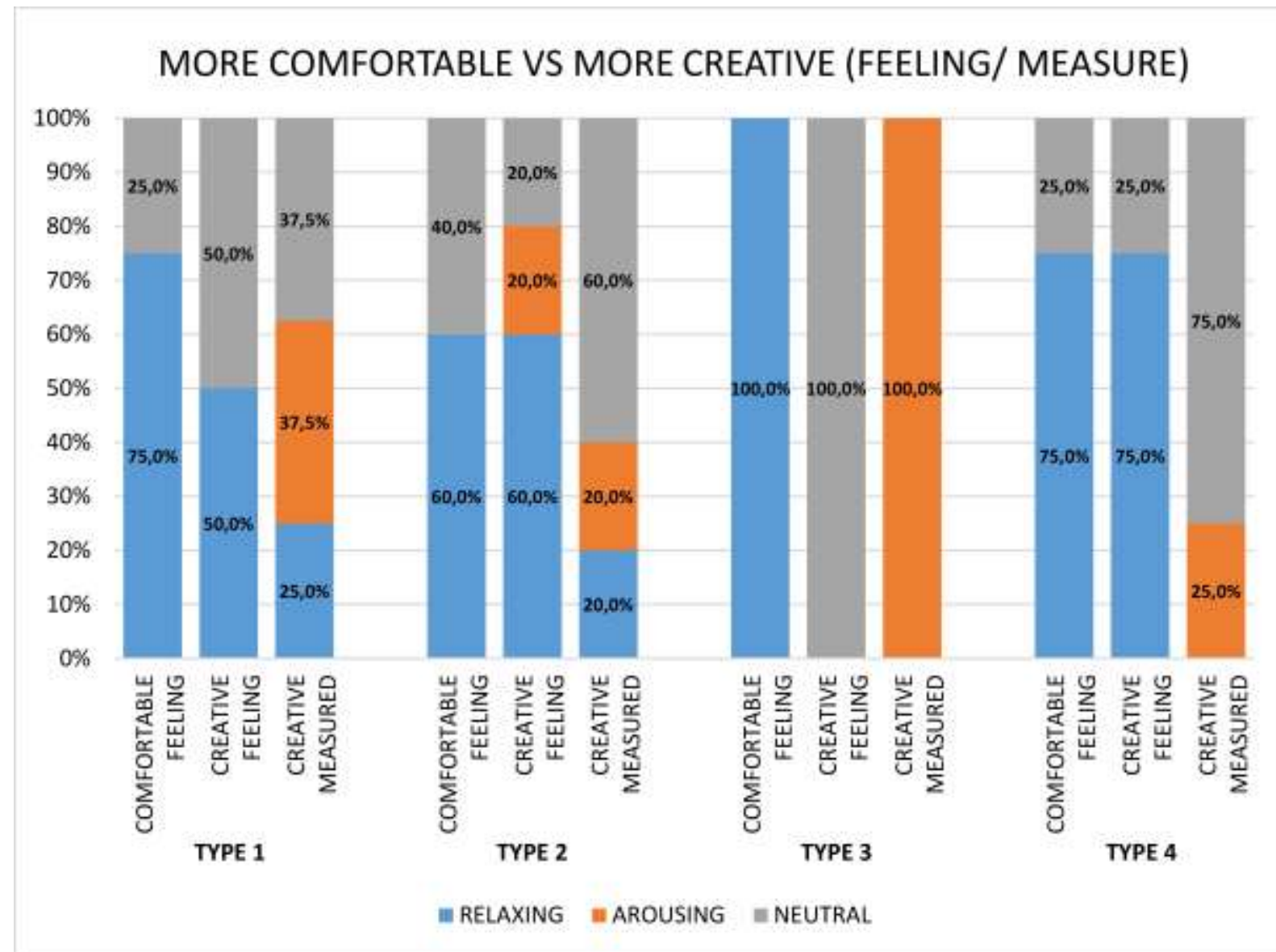


Figure 8. Comparison of the feelings experienced when working in each type of environment, expressed by each type of user in the surveys, and the creativity rating measured by means of CPSS.
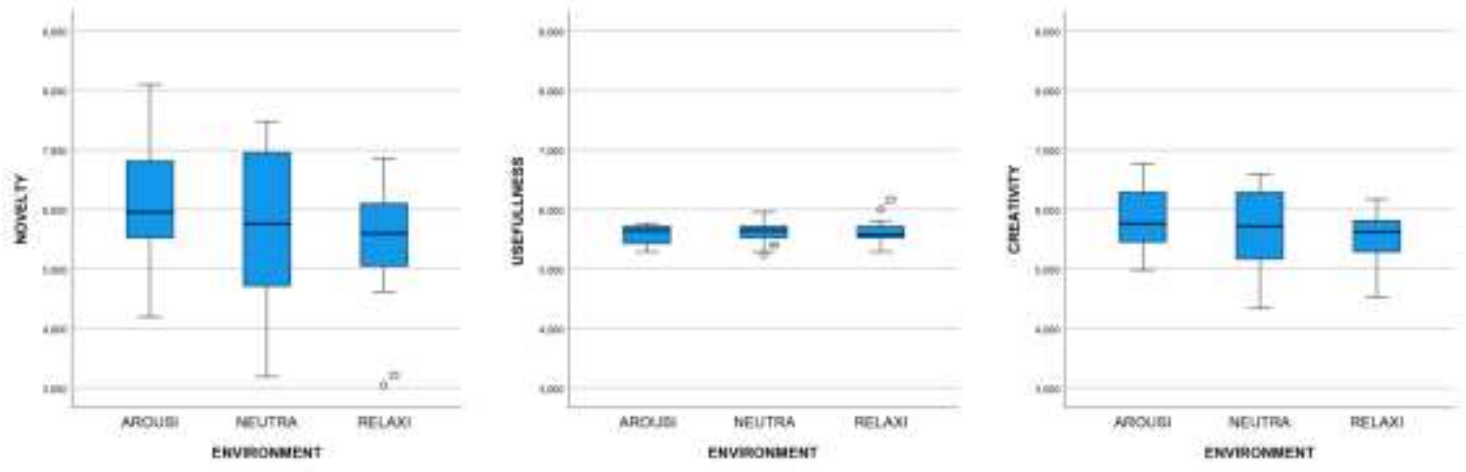

Figure 9. Creativity results measured by CPSS according to the type of environment.

The result of the creativity of the different conceptual design proposals, measured by CPSS, was also studied according to the work environment, the ratings being represented for each type of user. Figure 11 shows a box and whisker plot, in which the influence on the creativity value obtained in each type of work environment can be observed, according to the personality profile.
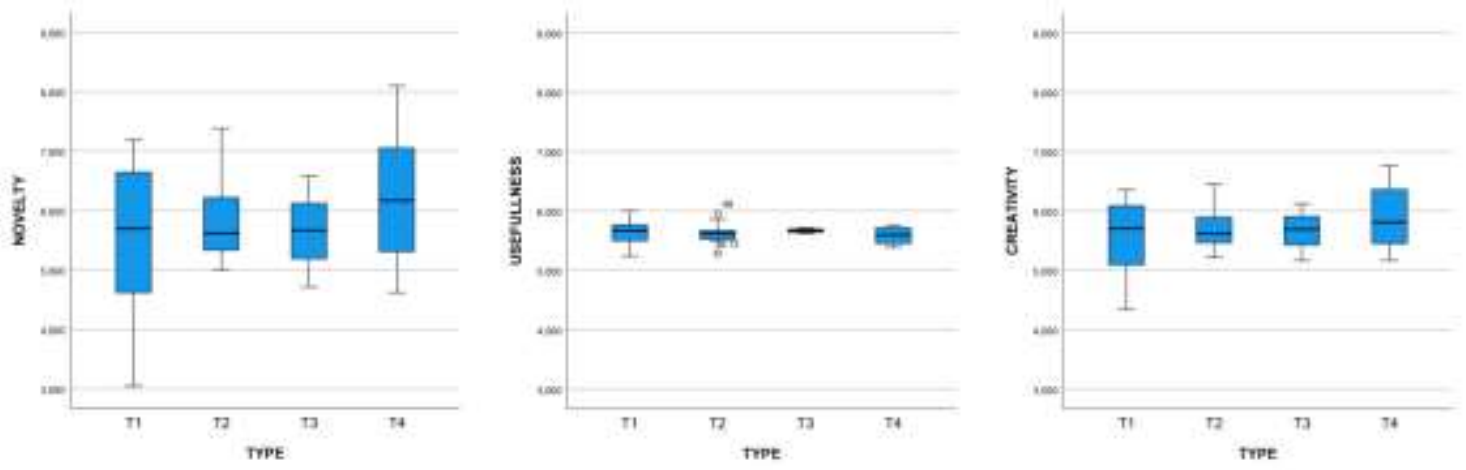

Figure 10. Results of creativity measured by means of CPSS according to the type of user. 

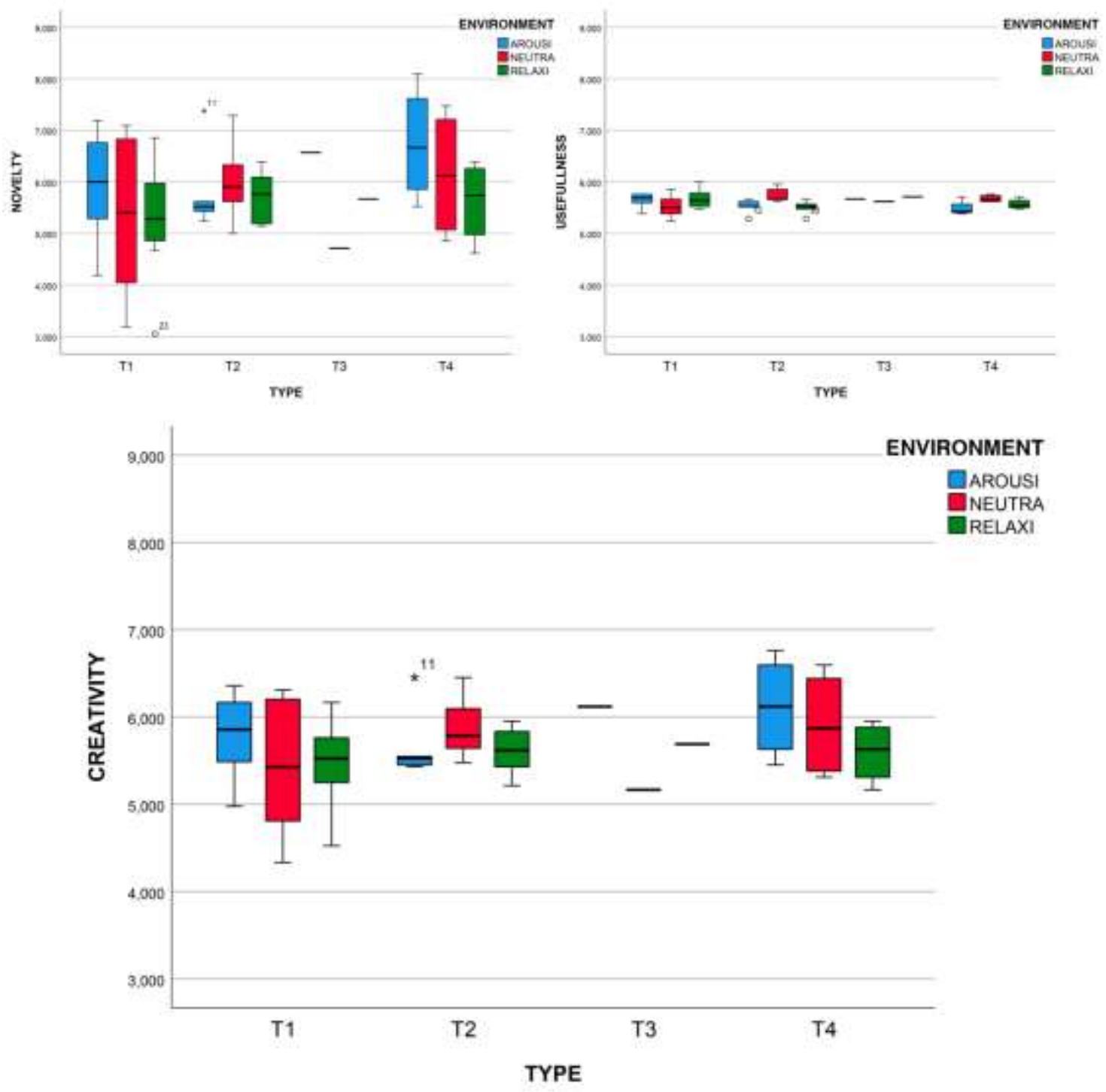

Figure 11. Results of creativity measured by means of CPSS according to the interaction between the type of user and environment

\section{Discussion}

As can be seen in Table 2, if the users who participated in the study are distributed in quadrants according to the values obtained when performing the NEO-FFI test, and taking the Neuroticism $(\mathrm{N})$ and Openness $(\mathrm{O})$ dimensions as a reference, a majority of type 1 users are observed, with high $\mathrm{N}$ and $\mathrm{O}$ values. This implies a good disposition towards change and a high rate of anxiety or emotional insecurity. In contrast, there was only one type 3 user, with low $\mathrm{N}$ and $\mathrm{O}$ values, that is, with a low level of adaptation to 
changes and low worry or emotional anxiety. Figure 5 shows the values obtained for each user in the corresponding quadrants. The rating of user 18 (type 3 ) stands out for being considerably farther from the neutral point of intersection of both axes (50/50). Also noteworthy is the high dispersion of the other users, concentrated in an area in the centre, but with little coincidence among the ratings.

Figure 6 shows that most users felt more comfortable in the relaxing environment, with only a few cases of type 1 and 4 users feeling more comfortable in the neutral environment. It should be noted that these types of users have a high value for openness and could therefore be expected to adapt easily to changes in the work environment. Most of them preferred the relaxing environment. It is remarkable that no user expressed a preference for the arousing environment when asked to rate the most comfortable.

Figure 7 highlights the fact that only one user claimed they felt more creative in the arousing room. This user belongs to type 3 , with a high $\mathrm{N}$ value and a low $\mathrm{O}$ value, and is therefore not especially open to change and displays a high degree of emotional insecurity. It is also noteworthy that in this case there are two users, of types 2 and 3 , who felt more creative in the neutral environment. Nevertheless, type 1 and 4 users expressed themselves in similar terms to those of the most comfortable case.

The correlation value of $r=0.443$, obtained among the different raters on applying the CPSS methodology to evaluate the creativity of the conceptual proposals developed in the study, is considered, according to the Pearson's correlation scale, a moderate positive correlation for the parameters of novelty and usefulness. It is thus considered as a valid appraisal.

Table 7 shows the traceability by user regarding which environment they said they felt most comfortable in, which they felt most creative in and which they were 
actually more creative in, according to the creativity ratings from the CPSS. There are few cases in which the three ratings coincide, such as user 11 (type 1) with the relaxing environment, or users 3 (type 1) and 9 (type 4) with the neutral environment. In this same sense, the correspondence between the environments in which each user felt more creative and the one in which them were actually more creative is very low. Cases that stand out in this regard are those of users 4 (type 1), 10 (type 2) and 8 (type 4), in which they claimed they felt more creative in the relaxing environment and were more creative in the arousing one, or even the case of user 16 (type 2), who said he or she felt more creative in the arousing environment, but was in fact more creative in the relaxing setting.

Figure 8 shows a comparative study along the lines of Table 7, but focused on the type of user rather than on each user in detail. Worthy of note are the values for type 3, with a sample consisting of only one user, where there is a clear inconsistency between what was stated on answering questions about the feeling of comfort, the feeling of creativity and the measurement of creativity, with one in each environment. Type 4 users feel more comfortable and more creative predominantly in the relaxing environment. The measurement of creativity by the CPSS, however, presents a clear predominance of the ratings of the conceptual designs carried out in the neutral room, and the absence of ratings in the relaxing room. It is interesting to note that in the whole ratings of creativity carried out by CPSS, the designs developed in the arousing and neutral environments predominate as the highest rated, while the highest valuated conceptual designs developed in relaxing environments are practically anecdotal. This would reinforce the idea that in order to encourage creativity it is desirable to maintain a neutral environment, or in any case an arousing one. 
On observing the results presented in Figure 9, it can be seen how the work environment has a very scant influence on usefulness. However, in the novelty parameter, there is an increase in creativity in the arousing environment and a greater dispersion of the sample in the values for the neutral environment. Hence, the results of creativity follow the same pattern as those of novelty, with an almost identical average value in all three environments.

Figure 10 shows the same pattern for the values of usefulness involving a comparison of the type of user, all of them being practically identical. In this case, type 4 users (high openness and low neuroticism) achieve higher novelty and creativity values, which is a result that can apparently be expected, since they display high openness to change and are barely affected by changes. Similarly, a consistent finding is that types 2 and 3 (low openness), who are not very open to change, have more concentrated dispersions and in general a lower value for novelty and creativity. Type 1 users, on the other hand, with a high disposition to changes, but who are strongly affected by such changes, present the greatest dispersion of values for novelty and creativity, which is to be expected given their less defined or ambiguous profile.

In the study of the statistical significance of the samples collected, conducted by means of variance analyses (ANOVA), with a value of $\alpha=0.05$, it can be seen that the only significant result is the Type-Environment interaction, with a value of $p=.041$. This implies that each type of person would achieve significantly different design results in terms of usefulness, depending on the combination between the environment they work in and their personality profile.

In this sense, Figure 11 represents the usefulness, novelty and creativity for each type of user and environment. From the ANOVA results, the significative differences are in the usefulness. Type 1 users, who are open to change and are thus affected to a 
far lesser extent by those changes, obtain higher usefulness values in the stimulating environments, that is, arousing and relaxing, with a lower value in the neutral ones. Despite the fact that in the boxplot (Figure 11) the boxes appear in a narrow range, it can be appreciated that they don't overlap in range. On observing the values of novelty and creativity, a similar pattern of behaviour is observed.

In the same way, type 2 users, who are resistant to change and are thus affected to a greater extent by such changes and can therefore be understood as the most conservative profile, present the totally opposite case. They obtain significantly higher values for usefulness in the neutral environment and significantly lower values in the stimulating settings, that is to say, the arousing and relaxing environments. On observing the values of novelty and creativity, the same pattern of behaviour is observed.

Type 4 users, who are open to change and are therefore unaffected by changes and can be understood as the most open profile of the four, obtain the highest values for usefulness in the neutral environment and lower values in the stimulated settings, that is, the arousing and relaxing environments. On observing the behaviour in the novelty and creativity parameters, however, the pattern is seen to be different. In this case, the values of the arousing environment stand out at a considerable distance from the others and from those of usefulness. Consequently, we can consider that the arousing environment enhances the creativity and novelty of the conceptual designs produced by the type 4 users, this being the highest value of all those achieved, followed by the values for creativity and novelty achieved by the same users.

It should be noted that, in this case, it is rather inappropriate to consider the results of type 3 users, as there is only one user in this group and the analysis could be misleading. Users of this type are resistant to change, although they are not affected by 
changes. Despite the low significance of the sample, in this case the behaviour of the usefulness values would be similar to that of type 1 users. Nevertheless, the creativity and novelty behaviour would be different from the others, with the values of the arousing environment standing out above the rest, followed by relaxing and a notably lower value for the neutral environment.

\section{Conclusions}

Perhaps the most interesting aspect of this study lies in the fact that it has shown that the type-environment interaction makes a significant contribution to the factor usefulness, which is consistent with the results analysed in the discussion. We can thus highlight the importance of characterising the different types of users who participate in the conceptual design process and of offering them the right work environment that favours their creativity, even though the choice of environment may contradict their perception of the environment in which they feel most creative or most comfortable.

It is also interesting to note that type 4 users working in an arousing environment are the ones who achieve the highest values for creativity and novelty. Likewise, type 2 users achieve their best results working in a neutral environment, albeit with values that are significantly lower than in the previous case. And type 3 users, although more similar, stand out for the usefulness of the proposals they developed in stimulating environments, whether arousing or relaxing. Therefore, the use of stimulating environments should not be generalised to all types of users, but rather each of them should be provided with the appropriate work environment according to their personality profile.

The initial hypothesis can be said to have been confirmed, as it has been shown that the personality profiles of the users who participated in the study have influenced 
the way in which the environment where they worked affected the creativity of the conceptual design proposals they developed.

In view of the results obtained, there is a need for future studies that assess the influence of the user's personality profile, together with other parameters that can make up the work environment, such as the use of open natural spaces or simulated natural spaces.

\section{Acknowledgements}

The research presented in this paper was funded by the Generalitat Valenciana Government (project ref. GV/2017/098 “Creación de espacios emocionales para incrementar los resultados creativos del diseñador durante la fase conceptual")

\section{References}

Aiello, J. R., DeRisi, D. T., Epstein, Y. M. \& Karlin, R. A. (1977). Crowding and the role of interpersonal distance preference, Sociometry, 40(3), 271-282.

Alencar, E. M. L. S. \& Bruno-Faria, M. F. (1997). Characteristics of an organizational environment which stimulate and inhibit creativity, Journal of Creative Behavior, 31(4), $271-281$

Alves, J., Marques, M. J., Saur, I. \& Marques, P. (2007). Creativity and innovation through multidisciplinary and multisectoral cooperation, Creativity and Innovation Management, 16(1), 27-34.

Amabile, T. M. (1996). Creativity in context: Update to the social psychology of creativity. Hachette UK.

Ceylan, C., Dul, J. \& Aytac, S. (2008). Can the office environment stimulate a manager's creativity?, Human Factors and Ergonomics in Manufacturing \& Service Industries, 18(6), 589-602. 
Chulvi, V., Mulet, E., Chakrabarti, A., López-Mesa, B., González-Cruz, C. (2012a). Comparison of the degree of creativity in the design outcomes using different design methods. Journal of Engineering Design, 23 (4), 241-269.

Chulvi, V., Mulet, E. \& González-Cruz, M. C. (2012b). Medida de la creatividad en productos: Métricas y objetividad, DYNA Ingenieria e Industria, 87(1), 80-89.

Csikszentmihalyi, M. (1998). Creatividad: el fluir y la psicología del descubrimiento y la invención. 41-71. Barcelona: Paidós

Justel D. (2008). Metodología para la eco-innovación en el diseño para desensamblado de productos industriales. Programa de doctorado: Proyectos de innovación tecnológica en ingeniería del producto y del proceso (Universitat Jaume I).

Knasko, S. C. (1992). Ambient odor's effect on creativ-ity, mood, and perceived health, Chemical Senses, 17(1), 27-35.

Kasof, J. (1997). Creativity and breadth of attention, Creativity Research Journal, 10(4), 303-315.

Knez, I. (1995). Effects of indoor lighting on mood and cognition, Journal of environmental psychology, 15(1), 39-51.

Kurt, M.Y. (2001). The effect of a computer simulation activity versus a hands-on activity on product creativity in technology education. Journal of Technology Education, 13(1), 31-43.

McCoy, J. M. \& Evans, G. W. (2002). The potential role of the physical environment in fostering creativity, Creativity Research Journal, 14(3-4), 409-426.

Mehta, R., Zhu, R. \& Cheema, A. (2012). Is noise always bad? Exploring the effects of ambient noise on creative cognition, Journal of Consumer Research, 39(4), 784-799. Michael, K. Y. (2000). A Comparison of Students' Product Creativity Using a Computer Simulation Activity Versus a Hands-On Activity in Technology Education. 
Ph.D. thesis, Faculty of the Virginia Polytechnic Institute and State University, Virginia.

Moss, J. (1966). Measuring creative abilities in junior high school industrial arts. American Council on Industrial Arts Teacher Education, Encino.

O'Quin, K. \& Besemer, S. P. (1989). The development, reliability, and validity of the revised creative product semantic scale, Creativity Research Journal, 2(4), 267-278. O'Quin, K. \& Besemer, S. P. (2006). Using the creative product semantic scale as a metric for results-Oriented business. Creativity and Innovation Management, 15 (1), 3444.

Sarkar, P. \& Chakrabarti, A. (2008). Studying Engineering Design Creativity.

Developing a Common Definition and Associated Measures. In: Invited Paper in the Proceedings of the NSF Workshop on Studying Design Creativity John Gero (Ed.). Shalley, C. E. \& Oldham, G. R. (1997). Competition and creative performance: Effect of competitor presence and visibility, Creativity Research Journal, 10(4), 337-345 Shibata, S. \& Suzuki, N. (2004). Effects of an indoor plant on creative task performance and mood, Scandinavian journal of psychology, 45(5), 373-381

Stokols, D., Clitheroe, C. \& Zmuidzinas, M. (2002). Qualities of work environments that promote perceived support for creativity, Creativity Research Journal, 14(2), 137147.

Stone, N. J. (1998). Windows and environmental cues on performance and mood, Environment and Behavior, 30(3), 306-321.

Stone, N. J. \& English, A. J. (1998). Task type, posters, and workspace color on mood, satisfaction, and performance, Journal of Environmental Psychology, 18(2), 175-185. Stone, N. J. \& Irvine, J. M. (1994). Direct or indirect window access, task type, and performance, Journal of Environmental Psychology, 14(1), 57-63. 
White, A. \& Smith, B.L. (2001). Assessing advertising creativity using the creative product semantic scale. Journal of Advertising Research, 41(6), 27-34. 